This is a self-archived version of an original article. This version may differ from the original in pagination and typographic details.

Author(s): Lesonen, Sirkku

Title: Vaihtelu vahvuutena : neljän suomi toisena kielenä -oppijan kielenkehittyminen dynaamisesta käyttöpohjaisesta näkökulmasta

Year: 2020

Version: Published version

Copyright: (c) 2020 Kotikielen seura

Rights: In Copyright

Rights url: http://rightsstatements.org/page//nC/1.0/?language=en

Please cite the original version:

Lesonen, S. (2020). Vaihtelu vahvuutena : neljän suomi toisena kielenä -oppijan kielenkehittyminen dynaamisesta käyttöpohjaisesta näkökulmasta. Virittäjä, 124(4).

https://doi.org/10.23982/vir.97613 


\title{
Vaihtelu vahvuutena
}

\section{Neljän suomi toisena kielenä -oppijan kielenkehittyminen dynaamisesta käyttöpohjaisesta näkökulmasta}

\author{
SIRKKU LESONEN
}

\section{Väitöksenalkajaisesitelmä Jyväskylän yliopistossa 25. elokuuta 2020}

Meillä on taipumus arvioida omia tuntemuksiamme ja meitä ympäröivää maailmaa. Mielessämme pyörii ajatuksia, kuten tämähän menee hyvin tai olipas se kivaa. Usein myös kuvailemme ympäristöämme, esimerkiksi täälläpä on tungosta. Väitöskirjassani olen keskittynyt tällaisiin arvioinnin ja jossakin on jotakin -tyyppisiin ilmauksiin. Olen kerännyt kirjoitettuja tekstejä ja puhenäytteitä neljältä ulkomaalaiselta yliopistoopiskelijalta viikoittain yhdeksän kuukauden aikana ja tutkinut, miten he ilmaisevat näitä kahta asiaa.

Arvioinneilla tarkoitan sellaisia ilmaisuja, jotka kertovat, että jokin asia on hyvä tai huono. Käytämme ja kohtaamme arvioivaa kieltä jatkuvasti. Pääministeri Sanna Marin kommentoi naimisiinmenoaan muutama viikko sitten Instagramissa kauniisti: Olen onnellinen ja kiitollinen, että saan jakaa elämäni rakastamani ihmisen kanssa. Myös tutkimukseni osallistujat kertovat teksteissään ja puhenäytteissään omista ihmissuhteistaan ja esittävät niistä arvioita. Aineistonkeruun kolmannella viikolla Khadiza kirjoittaa miehestään seuraavasti: Rafi on mun aviomies. Hyvä mies. Asia käy selväksi, mutta kielitaito näyttää vielä rajoittavan Khadizan ilmaisua siinä määrin, että arvio Rafista jää huomattavasti yksinkertaisemmaksi kuin Marinin kuvaus hääpäivän tunnelmista. Hyvä mies -ilmaus onkin oivallinen esimerkki alkeistason oppijan esittämästä arviosta, jossa hyvä-adjektiivi muodostaa arvion ytimen.

Yksi tutkimukseni päätulos on se, että kaikki tutkimani neljä oppijaa käyttävät pääasiassa kahta kielellistä keinoa ilmaistessaan arvioita: adjektiiveja ja verbejä. Hyvä mies -ilmaus on esimerkki arvioivasta eli evaluoivasta adjektiivikonstruktiosta, samoin ilmaus mun suomi on hieno. Arvioivia verbikonstruktioita puolestaan ovat ilmaukset kuten rakastan suomesta ja tykkään tomaatista. Pienessä kontrollitutkimuksessa tuli 
esille, että äidinkieliset puhujat käyttävät muunkin tyyppisiä kielellisiä keinoja arviointien ilmaisemiseen. Käytössä on myös substantiiveja, kuten ilmaisussa varsinainen kuntoilu tuottaa minulle tuskaa tai ne ovat ominaisuuksia, joista ei ole paljoa hyötyä. Lisäksi äidinkieliset ilmaisevat arvioita ilmauksilla, joista on vaikea osoittaa selkeää arvioivaa elementtiä, kuten ilmaisussa työ oli jopa sellainen, että sitä kehtaa näyttää muillekin. Alkeistason oppijoilla arviot ovat puolestaan yhden, selkeästi arvioivan sanan ympärille rakentuvia ja melko yksinkertaisia - kuten nyt ilmaus hyvä mies.

Sen lisäksi, että olen tutkinut niitä kielellisiä keinoja, joita oppijat käyttävät arviointien ilmaisemiseen, olen tutkinut myös näiden kielellisten keinojen kehittymistä yhdeksän kuukauden aikana. Keskeinen tulos on se, että viikoittain kerätyssä aineistossa kaikki oppijat käyttävät verbejä ja adjektiiveja melko selkeissä vaiheissa. Noin ensimmäiset kymmenen viikkoa kaikki käyttävät paljon ja monipuolisesti verbejä, kuten tykkään, pidän, rakastan ja haluan. Tällöin adjektiivien käyttö on vähäistä. Tämän verbivaiheen jälkeen jokaisella oppijalla on myös adjektiivivaihe, jolloin adjektiivien käyttö lisääntyy ja monipuolistuu selvästi. Hyvä-adjektiivin rinnalle tulee paljon muitakin adjektiiveja, kuten hieno, kiva, hauska, onnelilainen ja masentulinen. Kiinnostavinta tässä adjektiivivaiheessa on se, että verbien käyttö vähenee ja yksipuolistuu näillä viikoilla. Uuden kielellisen keinon käyttöönotto siis aiheuttaa taantumaa jo opitussa taidossa. Oppijoilla verbien käyttö ja adjektiivien käyttö ovat yhteydessä toisiinsa, ja siksi käyttämässäni teoreettisessa viitekehyksessä, dynaamisten systeemien teoriassa, puhutaankin kielen osasysteemien vuorovaikutuksesta (esim. de Bot \& Larsen-Freeman 2011: 10; van Geert \& Verspoor 2015: 539). Tässä tapauksessa on kyse kilpailevasta vuorovaikutussuhteesta, koska toista kielellistä keinoa käytetään toisen kustannuksella (van Geert 1991: 5, 21-23; Verspoor \& van Dijk 2011: 86).

Kahteen asiaan keskittyminen samaan aikaan on siis oppijalle vaikeaa. Tilanne on haastava myös opettajalle. Tulisiko opetuksessa keskittyä siihen asiaan, jota oppija käyttää, vai tulisiko koettaa ujuttaa opetukseen myös sitä toista asiaa? Tutkimukseni mukaan on järkevämpää keskittyä kilpailua johtavan elementin kehityksen tukemiseen. Tutkimukseni osallistujat kävivät seuranta-aikana kolme kielikurssia, ja käytettävissäni oli näiden kurssien materiaalit ja sisällöt. Kun oppijoilla oli verbivaihe, opetuksessa otettiin esille myös adjektiiveja. Kukaan oppija ei kuitenkaan oikein pystynyt ottamaan niitä käyttöönsä, eli opetuksen vaste ei tältä osin ollut erityisen hyvä ainakaan välittömästi. Myös aineistoni määrällinen analyysi tukee tätä tulkintaa. Verbivaiheessa verbien määrässä esiintyi enemmän vaihtelua viikosta toiseen kuin adjektiivien määrässä. Adjektiivien määrä pysyi siis viikosta toiseen tasaisempana kuin verbien määrä, jossa tapahtui hyppäyksiä ja pudotuksia. On ehdotettu, että juuri tällaisessa suuren vaihtelun vaiheessa pedagoginen interventio, eli siis asiaan keskittyvä opetustuokio, olisi kaikkein tehokkain. Liikkeessä olevaa asiaa on helpompi tönäistä kovaan vauhtiin kuin paikallaan jököttävää.

Olen analysoinut väitöskirjassani tarkemmin kahden arvioinnin ilmaisemiseen käytetyn verbikonstruktion kehittymistä. Kaikki oppijat käyttivät tiheästi verbejä haluta ja tykätä, ja näiden verbien käyttö ja kehitys haastavat mielenkiintoisella tavalla joitakin käyttämäni toisen teoreettisen viitekehyksen, käyttöpohjaisten kielenoppimisen mallien (esim. Langacker 1999; Barlow \& Kemmer 2000; Tomasello 2000) 
olettamuksia. Käyttöpohjaisuuteen perustuvassa kielenoppimisen tutkimuksessa on vakuuttavasti osoitettu, että lapset oppivat kieltä aloittaen ilmaisuilla, jotka ovat keskenään hyvin samanlaisia tai jopa identtisiä. Lapsi saattaa kielenoppimisen alkuvaiheessa käyttää toistuvasti esimerkiksi ilmausta anna maitoa. Ajan myötä lapsi kuulee myös muita ilmauksia, kuten anna vettä tai otatko maitoa. Pikkuhiljaa lapsi oppii erottelemaan näistä ilmauksista eri osia ja näiden osien funktioita. Lapsen kielessä ei siis enää olekaan vain könttämäisiä kokonaisia ilmauksia eli chunkeja, kuten anna maitoa, vaan nämä ilmaukset rakentuvat osista, eli esimerkiksi anna ja maitoa, ja koska näin on, näitä osia voidaan tilanteen vaatimusten mukaan myös vaihdella. Lapsi pystyykin siis pyytämään maidon lisäksi myös vettä ja myöhemmin varioimaan ilmauksiaan yhä enemmän ja esimerkiksi ymmärtämään kysymyksen otatko vettä. (Ks. esim. MacWhinney 1975; Tomasello 2000; Dąbrowska 2001.) Aikuisten kielenoppimisessa on havaittu samankaltaista pilkkomattomien ilmausten käyttöä (Mellow 2006; Eskildsen 2009, 2012, 2018), ja myös väitöskirjani aineistossa tällainen oppimispolku löytyi. Lenan haluta-konstruktio alkaa rakentua könttämäisestä ilmauksesta Haluaisin matkustaa Saksaan, ja vasta noin viiden viikon jälkeen haluta-verbi alkaa saada erilaisia täydennyksiä, kuten Marja haluaisi oppia englannin kieli ja Haluan myös kirjoittaa blogissa. Merkillepantavaa on kuitenkin se, että myös hyvin erilaisia oppimispolkuja löytyi. Toisella osallistujalla, Alvarolla, haluta-konstruktio on heti ensimmäisistä viikoista alkaen vaihteleva, eikä Alvarolla oppiminen näytä perustuvan pilkkomattomiin rakenteisiin. Samansuuntaisia tuloksia on löydetty vasta muutamassa aiemmassa kansainvälisessä tutkimuksessa (Mellow 2006; Eskildsen 2009, 2012, 2018), ja tämä löydös onkin tärkeä kielenoppimisen teorioiden eteenpäin kehittämisessä. Tätä tietoa voidaan hyödyntää myös opetuksessa. Sen lisäksi, että opetusmateriaali ja käytetyt harjoitukset sisältävät paljon kielellistä aineista, joka toistuu useasti samanlaisena, voi oppijoita jo melko varhaisessa vaiheessa auttaa huomaamaan ilmaisujen eri osien funktioita.

Tykätä-konstruktion kehitys puolestaan osoittaa, miten oppijat ovat hoksanneet suomen kielen toimivan. Jungo kirjoittaa viikolla seitsemän suomalaisista seuraavalla tavalla: Suomalainen ei tykkää venäjäläinenstä. Vaikka ilmaus ei ole suomen kielen normien mukainen, se itse asiassa osoittaa, miten Jungo on napannut idean suomen kielen päätteiden käytöstä. Kun maan nimeen Venäjä liittää päätteen -läinen, muodostuu adjektiivi, Jungon kielessä siis venäjäläinen. Koska tykätä-verbi vaatii elatiivin päätteen -stA, laittaa Jungo tämän päätteen suoraan sanan perään eli siis venäjäläinenstä. Jungo käyttää siis selkeästi sääntöjä apunaan kertoessaan suomalaisista. On epätodennäköistä, joskaan ei tietenkään täysin poissuljettua, että Jungo olisi kuullut tällaisen ilmauksen ja napannut sen omaan kielenkäyttöönsä. Tällainen kielen normien vastainen ilmaus voi kertoa kielentutkijalle paljon oppijan käyttämästä logiikasta, ja se voi kertoa myös opettajalle paljon siitä, mitä oppija jo osaa.

Toinen tutkimani merkitys on eksistentiaalisuus. Eksistentiaalisuuden ilmaisuissa kerrotaan, että jossakin on jotakin. Eksistentiaalikonstruktio on esimerkiksi ilmaus Suomessa on paljon järviä. Tämä konstruktio on suomen kielessä monessa mielessä erikoinen (VISK $\$ 893$ ). Esimerkiksi verbi on yksikössä, vaikka subjekti onkin monikossa. Emme siis sano Suomessa ovat paljon järviä. Erikoista on myös se, että subjekti on joskus partitiivissa. Eli siis Suomessa on paljon järviä, ei Suomessa on paljon järvet. 
Näiden syiden takia eksistentiaalikonstruktiota on pidetty usein vaikeasti opittavana. Myös väitöskirjani osallistujat alkavat käyttää eksistentiaalirakennetta melko myöhään, vasta suunnilleen seitsemän kahdeksan kuukauden jälkeen. Kaksi osallistujaa koettaa kuitenkin ilmaista tätä merkitystä paljon aikaisemmin, mutta heillä ei ole vielä käytössään suomen kielen konventionaalista eksistentiaalikonstruktiota. He käyttävätkin epäkonventionaalisia eli äidinkielisen puhujan korvaan hassulta kuulostavia ilmauksia, kuten se on paljon järviä Suomessa, Suomi on maa paljon järvien kanssa, siellä on paljon järviä Suomessa tai on olemassa paljon järviä.

Tutkimukseni on ensimmäinen, joka systemaattisesti tutkii näitä oppijoiden omia eksistentiaalisuuden ilmaisuja niiden omista lähtökohdista. Eksistentiaalikonstruktiota on kyllä tutkittu aikaisemminkin (esim. Kajander 2013), mutta tällöin analyysin ulkopuolelle ovat jääneet nämä epäkonventionaaliset oppijankielen ilmaisut, sillä analyysiin ovat päässeet mukaan vain ne ilmaisut, jotka täyttävät tietyt ehdot konstruktion muodosta, kuten sen, että ilmaus alkaa paikkaan viittaavalla sanalla. Omassa tutkimuksessani analyysi on aloitettu merkityksestä, eli aina kun oppija ilmaisee, että jossakin on jotakin, ilmaus on otettu mukaan analyysiin, vaikka se olisi miten kummallinen. Tämä onomasiologinen lähestymistapa (ks. Grzega 2012; Fernández-Domínguez 2019) etsii siis kielellisiä ilmauksia tietylle ajatukselle tai ilmiölle, ja sen käyttäminen oppijankielen tutkimuksen lähtökohtana on kansainvälisestikin uutta.

Onomasiologisen lähestymistavan käyttö mahdollisti siis uusien oppijankielen konstruktioiden tunnistamisen, mikä on jo sinällään arvokasta. Tuloksilla on myös pedagogista sovellusarvoa. Tutkimukseni osoittaa, että osa oppijoista yrittää ilmaista sitä, että jossakin on jotakin, jo paljon ennen ensimmäistä aiheeseen keskittyvää opetustuokiota. Ensimmäinen epäkonventionaalinen eksistentiaalikonstruktio ilmestyy yhden osallistujan, Lenan, tekstiin jo viikolla 10, kun eksistentiaalirakenne tuli opetuksessa esille viikolla 15 ja oli toden teolla opetuksen teemana vasta viikolla 26. Opetus siis laahasi Lenan ilmaisutarpeita jäljessä viikkoja, jopa kuukausia. Olisi tietenkin järkevää opettaa eksistentiaalikonstruktio silloin, kun oppijalla on tarve tämän rakenteen käytölle. Ja kuten jo arviointien ilmaisujen kohdalla tuli esille, opetus on tehokkainta silloin, kun oppijankielessä on paljon vaihtelua. Esimerkiksi Lenan kohdalla opetuksen vaste voisi olla erinomainen niinä viikkoina, kun hän kokeilee useita erilaisia tapoja ilmaista sitä, että jossakin on jotakin.

Vaihteluun liittyy vielä yksi keskeinen väitöskirjani tulos. Lena, joka kokeilee useita erilaisia keinoja ilmaista eksistentiaalisuutta, ja jonka kielessä on siis eniten vaihtelua, kehittyi suomen kielessä neljästä oppijasta selvästi eniten yhdeksän kuukauden aikana. Vaihtelun määrän on osoitettu olevan yhteydessä menestykselliseen kielenoppimiseen myös muutamassa muussa viimeaikaisessa dynaamisten systeemien teoriaan perustuvassa tutkimuksessa (esim. Lowie \& Verspoor 2018). Näyttääkin siltä, että erilaisten ilmaisutapojen vaihtelu vie oppijaa eteenpäin ja valmistaa täsmällisempään suoritukseen. Kielenoppimista voi verrata voimisteluun. Uutta liikettä opetteleva voimistelija horjuu puomilla, ja juuri tämä horjuminen valmistaa hänen kehoaan liikkeen vaatimuksiin. Myös kielenoppimisessa horjuminen on hyödyllistä.

Tutkimukseni tulokset siis osoittavat, että kokeilunhalu ja seikkailumieli ovat kielenoppijalle vahvuus. Yksi esimerkki tällaisesta seikkailumielestä on Lenan arvio 
hänen omasta oppimisprosessistaan aineistonkeruun viimeisellä viikolla. Kuten muutkin oppijat Lena oli tähän saakka käyttänyt lähes yksinomaan adjektiiveja ja verbejä arvioidessaan asioita, mutta viimeisellä viikolla hän käyttääkin uutta kielellistä keinoa, substantiivia seikkailu arvioidessaan kokemustaan suomen oppimisesta: se oli seikkailu minulle, mennä tuntematon maahin ja oppia tuntematon kieli. Kielenoppiminen voi siis olla oppijalle seikkailu, mutta myös tutkijan näkökulmasta oppijankielen analyysi voi paljastaa jännittäviä piirteitä. Hollantilaiset tutkijat van Dijk ja van Geert (2007) kuvaavat osuvasti, miten oppijankielessä voi esiintyä "horjumista, kumpareita ja yllättäviä loikkauksia" eli "wobbles, humps and suddens jumps". Väitöskirjani osoittaa, että juuri näiden yllättävien muutosten eli kielessä esiintyvän vaihtelun tutkiminen voi avata uusia ikkunoita oppijoiden tapaan ilmaista ajatuksiaan ja käyttää suomen kieltä.

\section{Lähteet}

Barlow, Michael - Kemmer, Suzanne 2000: Introduction. A usage -based conception of language. - Michael Barlow \& Suzanne Kemmer (toim.), Usage-Based Models of Language s. vii-xxviii. Stanford: the Center for the Study of Language and Information (CSLI) Publications.

Bot, Kees de - Larsen-Freeman, Diane 2011: Researching second language development from a dynamic systems theory perspective. - Marjolijn Verspoor, Kees de Bot \& Wander Lowie (toim.), A dynamic approach to second language development. Methods and techniques s. 5-23. Amsterdam: John Benjamins Publishing Company.

DĄBROWSKA, EwA 2001: From formula to schema. The acquisition of English questions.

- Cognitive Linguistics 11 s. 83-102. https://doi.org/10.1515/cogl.2001.013.

Dijk, Marijn van - Geert, Paul van 2007: Wobbles, humps and sudden jumps: A case study of continuity, discontinuity and variability in early language development. - Infant and Child Development 16 s. 7-33. https://doi.org/10.1002/icd.506.

EsKildDEn, Søren 2009: Constructing another language. Usage-based linguistics in second language acquisition - Applied Linguistics 30 s. 335-357. http://doi.org/10.1093/applin/amno37.

- 2012: L2 negation constructions at work. - Language Learning 62 s. 335-372. https://doi. org/10.1111/j.1467-9922.2012.00698.x.

- 2018: L2 constructions and interactional competence. Subordination and coordination in English L2 learning. - Andrea Tyler, Lihong Huang \& Hana Jan (toim.), What is applied cognitive linguistics? s. 63-98. Berlin: De Gruyter. https://doi.org/10.1515/9783110572186-003

Fernández -Domínguez, Jesús 2019: The onomasiological approach. - Mark Aronoff (toim.), Oxford research encyclopedia of linguistics. Oxford: Oxford University Press. https://doi.org/10.1093/acrefore/9780199384655.013.579.

Geert, Paul van - Verspoor, Marjolijn 2015: Dynamic systems and language development. - Brian MacWhinney \& William O'Grady (toim.), The handbook of language emergence s. 537-555. Hoboken: Wiley Blackwell.

Geert, Paul van 1991: A dynamic systems model of cognitive and language growth. Psychological Review 98 s. 3-53. https://doi.org/10.1037/0033-295X.98.1.3.

GrzegA, JoACHim 2012. Lexical-semantic variables. - Juan Hernández-Campoy \& Juan Conde-Silvestre (toim.), The handbook of historical sociolinguistics s. 271-292. Chichester: Blackwell Publishing Ltd. 
Kajander, Miк ко 2013: Suomen eksistentiaalilause toisen kielen oppimisen polulla. Jyväskylä Studies in Humanities 220. Jyväskylä: Jyväskylän yliopisto. http://urn.fi/ URN:ISBN:978-951-39-5530-4.

LANGACKer, Ronald 1999: Grammar and conceptualization. Berlin: Mouton de Gruyter.

LOWIE, WANDER - Verspoor, MARJOLIJN 2018: Individual differences and the ergodicity problem - Language Learning 69 s. 184-206. https://doi.org/10.1111/lang.12324.

MacWhinney, Brian 1975: Pragmatic patterns in child syntax. - Stanford Papers and Reports on Child Language Development 10 s. 153-165.

Mellow, J. Dean 2006: The emergence of second language syntax. A case study of the acquisition of relative clauses - Applied Linguistics 27 s. 645-67o. https://doi.org/10.1093/applin/ amlo31.

Tomasello, Michael 200o: First steps toward a usage-based theory of language acquisition - Cognitive Linguistics 11 s. 61-82. https://doi.org/10.1515/cogl.2001.012.

Verspoor, Marjolin - Dijk, Marijn van 2011: Visualizing interactions between variables. - Marjolijn Verspoor, Kees de Bot \& Wander Lowie (toim.), A dynamic approach to second language development. Methods and techniques s. 85-98 Amsterdam: John Benjamins Publishing Company.

ViSK = Hakulinen, Auli - Vilkuna, Maria - Korhonen, Rittta - Koivisto, Vesa - Heinonen, Tarja Rittta \& Alho, Irja 2004. Iso suomen kielioppi. Helsinki: Suomalaisen Kirjallisuuden Seura. http://scripta.kotus.fi/visk. URN:ISBN:978-952-5446-35-7.

Sirkku Lesonen: Valuing Variability: Dynamic Usage-Based Principles in the L2 Development of Four Finnish Language Learners. Groningen Dissertation in Linguistics. 184. Groningen: University of Groningen 2020. Kirja on luettavissa osoitteessa http://urn.fi/ URN:ISBN:978-94-034-2675-4.

Kirjoittajan yhteystiedot: etunimi.sukunimi@jyu.fi 